\title{
Differential effects of extinction on behaviors maintained by concurrent schedules of primary and conditioned reinforcement
}

J. ZIMMERMAN AND P. V. HANFORD

INDIANA UNIVERSITY SCH COL OF MEDICINE AND INDIANA UNIVERSITY, INDIANAPOLIS CAMPUS

Pigeons were intermittently reinforced with grain for pecking at one key. Concurrent pecking at a second key intermittently produced conditioned reinforcement (CR). Under the se conditions, responding on the second key (a) was maintained indefinitely with $\mathrm{CR}$, (b) was markedly weakened by removing $C R$, and $(c)$ was independent of grain responding and relatively insensitive to grain manipulation.

Zimmerman (1963) described a two-key procedure for studying conditioned reinforcement (CR) with pigeons. Left-key responses were reinforced with grain on a VI schedule while right-key responses concurrently produced CR (1/2-sec presentation of stimuli paired with grain) on an independent VI schedule. This procedure maintained CR responding indefinitely and rates and patterns of CR responding were found to be appropriate to the CR schedule programmed. Zimmerman \& Hanford (1966) described a related one-key procedure. Pecking produced CR on a VI schedule while grain was concurrently presented freely via an independent VI tape if or after no peck was emitted for at least six sec. This procedure also maintained pecking indefinitely. By programming twocomponent multiple schedules, it was shown that pecking was sustained when it produced CR but was markedly weakened or extinguished following either the removal of $C R$ or its replacement with a set of neutral stimuli. In the present study (a) we attempted to replicate the Zimmerman \& Hanford (1966) results with the Zimmerman (1963) procedure and (b) we examined the relationship between grain responding and $\mathrm{CR}$ responding under grain and/or CR extinction.

\section{Procedure}

Four adult, male, White Carneaux pigeons served as Ss. Each had at least nine months exposure to conditions similar to those in the Zimmerman (1963) study, and CR pecking over this period was maintained indefinitely. During the last four months of this period each performed with a transparent shutter covering the grain aperture except when grain reinforcement was programmed (see Leckrone, Zimmerman, \& Hanford, 1966). Immediately prior to the present study, each $\mathrm{S}$ performed under conditions similar to those used as the baseline conditions of the present study. The left key was yellow and responses were reinforced with $3-\mathrm{sec}$ access to grain on a VI 2 schedule. Concurrently, the right key was either blue or green (these alternating every $5 \mathrm{~min}$ ) and responses in either color continuously postponed grain reinforcement for at least $4 \mathrm{sec}$ and intermittently produced CR (1/2-sec magazine cycle with the shutter closed) on a VI 1 schedule.

Throughout the present study, each S was maintained at $80 \%$ of its free-feeding weight and exposed daily to a 75-min session in which a given two-component multiple schedule of grain reinforcement (left key) and concurrent CR (right key) was programmed. The baseline condition was the same as that described in the previous paragraph except that the yellow (grain) light was replaced with white and red lights. Thus, in the first component the grain and CR keys were white and blue, respectively, while in the second component they were red and green, respectively. Each $S$ was exposed to a given multiple schedule until its rates stabilized (showed no consistent trend) for four successive sessions. Table 1 presents the order and nature of the schedules to which each $\mathrm{S}$ was exposed over the course of the study. Each was first exposed to a schedule in which the CR baseline (VI 1 , VI 1) was in effect while concurrently grain was only available in the presence of the white light (VI 2, EXT). Over the ensuing nine conditions (2 through 10) the grain baseline (VI 2, VI 2) was in effect while the CR schedule was manipulated. In the five even conditions the CR baseline was programmed. No $\mathrm{S}$ required more than 16 sessions to stabilize under any of these and in most cases only

Table 1

Order and Nature of Multiple Schedules

\begin{tabular}{|c|c|c|c|c|c|c|}
\hline \multirow{2}{*}{$\begin{array}{l}\text { Condition } \\
\text { Number }\end{array}$} & \multirow{2}{*}{$\begin{array}{l}\text { Grain Key } \\
\text { White, Red }\end{array}$} & \multirow{2}{*}{$\begin{array}{c}\text { CR Key } \\
\text { Blue, Green }\end{array}$} & \multicolumn{4}{|c|}{ Number of Sessions } \\
\hline & & & $14 R$ & $63 \mathrm{~W}$ & $3 R$ & $16 R$ \\
\hline 1 & GR, EXT & $C R, C R(B)$ & 30 & 29 & 29 & 28 \\
\hline $2,4,6,8,10$ & $G R, G R(B)$ & (B) & \multicolumn{4}{|c|}{ (See text) } \\
\hline 3 & (B) & EXT, CR & 18 & 13 & 10 & 10 \\
\hline 5 & (B) & $C R, E X T$ & 9 & 10 & 9 & 6 \\
\hline 7* & (B) & CR, NS & 12 & 9 & 7 & 11 \\
\hline 9* & (B) & NS, CR & 12 & 6 & 7 & 7 \\
\hline 11 & EXT, EXT & (B) & 16 & 15 & 8 & 13 \\
\hline 12 & (B) & (B) & $\cdots$ & 7 & 6 & 12 \\
\hline 13 & EXT, EXT & $C R, N S$ & 23 & $\cdots$ & $\cdots$ & 23 \\
\hline & EXT, EXT & NS, CR & $\cdots$ & 7 & 8 & $\cdots$ \\
\hline
\end{tabular}

Code: GR - grain reinforcement (VI 2); CR - Conditioned reinforcement (V| 1); NS - Neutral stimuli (VI 1); (B) - baseline condition. * 14R exposed to Condition 9 first. 


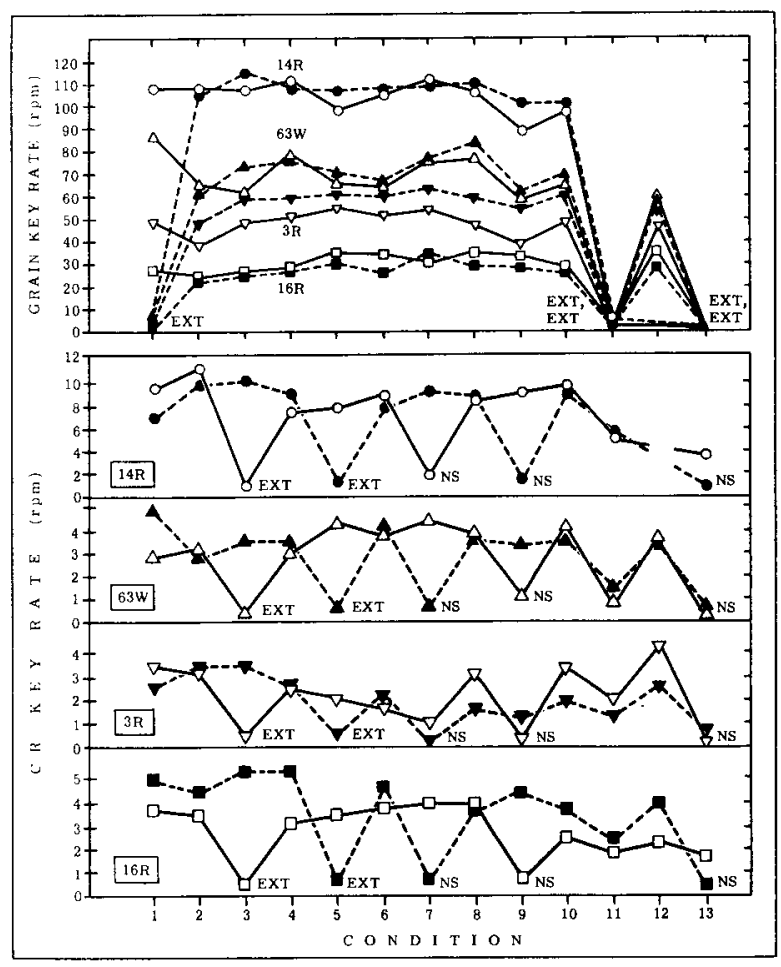

Fig. 1. Median rates of grain responding (upper curves) and $C R$ responding (lower curves) for each $S$ under each multiple schedule. Open points (solid lines) and closed points (dotted lines) represent the 1st and znd components, respectively. Where not otherwise indicated, the grain schedule is VI $2, V I 2$ and CR schedule is VI 1, VI 1. EXT indicates extinction and NS indicates substitution of neutral stimuli for $\mathbf{C R}$

five to 10 sessions were required. In the odd conditions $\mathrm{CR}$ was programmed in only one of the two components. $\mathrm{CR}$ was removed from the alternative component (3rd and 5th conditions) or replaced with a set of neutral stimuli, NS (7th and 9th conditions). This set of stimuli (never paired with grain) consisted of the presentation of a $400 \mathrm{cps}$ tone and $10 \mathrm{cps}$ flashing of the house lights. The CR baseline was in effect in the 11th and 12th conditions while grain was completely removed and then reinstated, respectively, in these conditions. In the final condition, grain was again completely removed while, concurrently, the NS replaced CR in one of the two components. Results and Discussion

Figure 1 summarizes the results. Each point presents the median rate (responses/min) of grain responding or $\mathrm{CR}$ responding in a given component based on the final five sessions under a given condition. Under most of the schedules, similar performances were obtained in all Ss. During the 2nd through 10th conditions (a) CR responding was maintained indefinitely as long as $\mathrm{CR}$ was available, (b) $\mathrm{CR}$ rates markedly decreased whenever $\mathrm{CR}$ was removed or replaced with NS, and (c) CR rates increased whenever $\mathrm{CR}$ was returned following its removal. These results systematically replicate those obtained by Zimmerman \& Hanford (1966) with the one-key procedure.

Most of the other results are provocative in that they suggest that performances maintained by $\mathrm{CR}$ under the present conditions are relatively independent of grain performances and relatively insensitive to grain manipulations. Over the 2nd through 10th conditions, grain rates were (a) five to 20 times greater than concurrent $\mathrm{CR}$ rates, (b) relatively stable across all conditions, and (c) apparently uninfluenced by $\mathrm{CR}$ manipulation. Slight changes in grain rates were often obtained when a CR condition was changed, but these rate shifts were inconsistent both within and across Ss. In addition, CR responding was well maintained in both components throughout exposure to the first condition (rates were actually higher in the grain extinction component for $63 \mathrm{~W}$ and 16R) in spite of the fact that this exposure lasted for a month and grain responding extinguished in the extinction component. Furthermore, although CR rates decreased when grain was totally removed (11th condition), they were still higher in both components (14R, 16R) or at least in one $(63 \mathrm{~W}, 3 \mathrm{R})$ than those obtained previously under CR extinction or NS components. These results were obtained in spite of the fact that (a) grain extinction was in effect for at least as long as the previous conditions, and (b) grain responding extinguished. Finally, CR rates of both 14R (the S not exposed to the 12th condition) and 16R decreased only slightly in the CR component of the final condition in spite of the fact that grain continued to be absent for an additional 28 days (14R) or for 23 days after exposure to the 12th condition (16R). The last two sets of results indicate that at least under or following some experimental conditions, $\mathrm{CR}$ can maintain performance in some Ss for a considerable period of time in the absence of primary reinforcement. Such results are rarely obtained with extinction procedures (see Kelleher \& Gollub, 1962) and suggest that the role of $\mathrm{CR}$ in the analysis of behavior be reconsidered by those investigators who have deemphasized it on the basis of extinction procedure results.

\section{References}

Kelleher, R. T., \& Gollub, L. R. A review of positive conditioned reinforcement. J. exp. Anal. Behav., 1962, 5, 543-597.

Leckrone, W. R., Zimmerman, J., \& Hanford, P. V. A pigeon magazine shutter for preventing unprogrammed grain reinforcement. Psychon. Sci., 1966, 6, 239-240.

Zimmerman, J. Technique for sustaining behavior with conditioned reinforcement. Scicncc, 1963, 142, 682-684.

Zimmerman, J., \& Hanford, P. V. Sustaining behavior with conditioned reinforcement as the only response-produced consequence. P.sychol. Rcp., 1966, 19, 391-401.

\section{Note}

1. This investigation was supported, in part, by Research Grant No. MH 10741 from the National Institute of Mental Health. 